\title{
Immunity and inflammation: the neglected key players in congenital heart disease?
}

\author{
Laura M. Wienecke ${ }^{1,2,3,5}$ - Sarah Cohen ${ }^{4} \cdot$ Johann Bauersachs ${ }^{1} \cdot$ Alexandre Mebazaa $^{2,3}$. \\ Benjamin G. Chousterman ${ }^{2,3}$
}

Accepted: 25 October 2021/Published online: 2 December 2021

(c) The Author(s) 2021

\begin{abstract}
Although more than $90 \%$ of children born with congenital heart disease (CHD) survive into adulthood, patients face significantly higher and premature morbidity and mortality. Heart failure as well as non-cardiac comorbidities represent a striking and life-limiting problem with need for new treatment options. Systemic chronic inflammation and immune activation have been identified as crucial drivers of disease causes and progression in various cardiovascular disorders and are promising therapeutic targets. Accumulating evidence indicates an inflammatory state and immune alterations in children and adults with CHD. In this review, we highlight the implications of chronic inflammation, immunity, and immune senescence in CHD. In this context, we summarize the impact of infant open-heart surgery with subsequent thymectomy on the immune system later in life and discuss the potential role of comorbidities and underlying genetic alterations. How an altered immunity and chronic inflammation in CHD influence patient outcomes facing SARS-CoV-2 infection is unclear, but requires special attention, as CHD could represent a population particularly at risk during the COVID-19 pandemic. Concluding remarks address possible clinical implications of immune changes in CHD and consider future immunomodulatory therapies.
\end{abstract}

Keywords Congenital heart disease $\cdot$ Inflammation $\cdot$ Heart failure $\cdot$ Thymectomy $\cdot$ COVID-19

\section{Introduction}

Advances in medical care have led to a substantially higher population of patients with congenital heart disease (CHD) with an estimated prevalence of around 1.9 million children

Laura M. Wienecke

Laura.Wienecke@med.uni-heidelberg.de

1 Department of Cardiology and Angiology, Hannover Medical School, Carl-Neuberg-Str. 1, 30621 Hannover, Germany

2 Department of Anaesthesiology and Critical Care, Lariboisière University Hospital, DMU Parabol, AP-HP Paris, France

3 Inserm U942 MASCOT, Université de Paris, Paris, France

4 Congenital Heart Diseases Department, M3C Hospital Marie Lannelongue, Université Paris-Saclay, Plessis-Robinson, Paris, France

5 Department of Cardiology, Angiology and Respiratory Medicine, Heidelberg University Hospital, Heidelberg, Germany and 2.3 million adults with CHD in Europe [1]. However, these patients still suffer from markedly higher and premature morbidity and mortality [2,3]. Heart failure (HF) constitutes the common central issue in CHD, despite the wide heterogeneity of various congenital heart defects [2]. Indeed, leading causes of death in adults with CHD (ACHD) are heart failure (43\%), infections such as pneumonia and endocarditis (12\%), as well as sudden cardiac death (7\%) [2].

CHD-related HF (CHD-HF) should always be considered separately from non-congenital HF as they arise from different etiologies. CHD-HF is more often characterized by a leading right rather than left ventricular failure and includes a lifelong chronic cardiac impairment with frequent surgical corrections or interventions (depending on the distinct malformations). Clinical care of CHD patients focuses predominantly on hemodynamics and treatment of complications and comorbidities [4]. To date, prevention as well as evidence-based treatments for CHD-HF are lacking apart from open heart surgery or interventional therapy.

Systemic chronic inflammation and immune activation have been identified as crucial drivers of disease development and progression, and they came up as promising 
therapeutic targets in non-congenital HF and other cardiovascular diseases [5]. However, they have not been evaluated sufficiently for the management of CHD, even though recent reports describe several elevated inflammation-related markers with prognostic impact in CHD [6,7].

The immune system includes innate and adaptive immune strategies to combat pathogen- or tissue damage-associated harm of the host organism. Next to innate and adaptive immune activation caused by HF itself, thymus removal could have an impact on adaptive immunity in CHD [8]. Corrective cardiothoracic surgery of malformations using a median sternotomy routinely includes the removal of thymus tissue to access the operation field-the heart and its great vessels. Surgical repair in CHD is often performed during the first years of life, which represents a crucial period regarding thymic lymphocyte production. As a consequence, several studies observed immune alterations such as pronounced immune senescence with reduced naïve and increased senescent $T$ cell subsets [8]. Therefore, CHD patients represent a very interesting and complex cohort from an immunological point of view.

CHD may originate from genetic or idiopathic causes and displays a large phenotypic diversity that may explain the variety of observed cardiac and immune alterations. The most common genetic syndromes linked to congenital heart malformations are Down syndrome (Trisomy 21), DiGeorge syndrome, and Noonan syndrome [9]. All three are related to immune deficiency, senescence, and increased risk for malignancies of the hematopoietic system, suggesting an underlying link between the development of the heart and of the immune system.

In this review, we aim to highlight the current knowledge and clinical implications regarding innate and adaptive immune alterations, inflammation and thymectomy in children and adults with CHD. Especially considering the COVID-19 pandemic, we will shed light onto the potential impact of $\mathrm{T}$ cell senescence, genetic syndromes, and chronic inflammation on patient outcomes upon SARS-CoV-2 infection. Although immunologists have investigated the immune changes in CHD for decades, a lot of cardiologists, pediatric cardiologists, and cardiothoracic surgeons are not aware of these insights.

\section{Causes and consequences of inflammation and immune changes in CHD}

Heart failure relates to chronic inflammation mediated primarily by innate immune activation. Indeed, alterations regarding cellular and humoral effectors of the innate immunity were observed in CHD (Tables 1 and 2, Fig. 1). Immune alterations of the adaptive immune system are

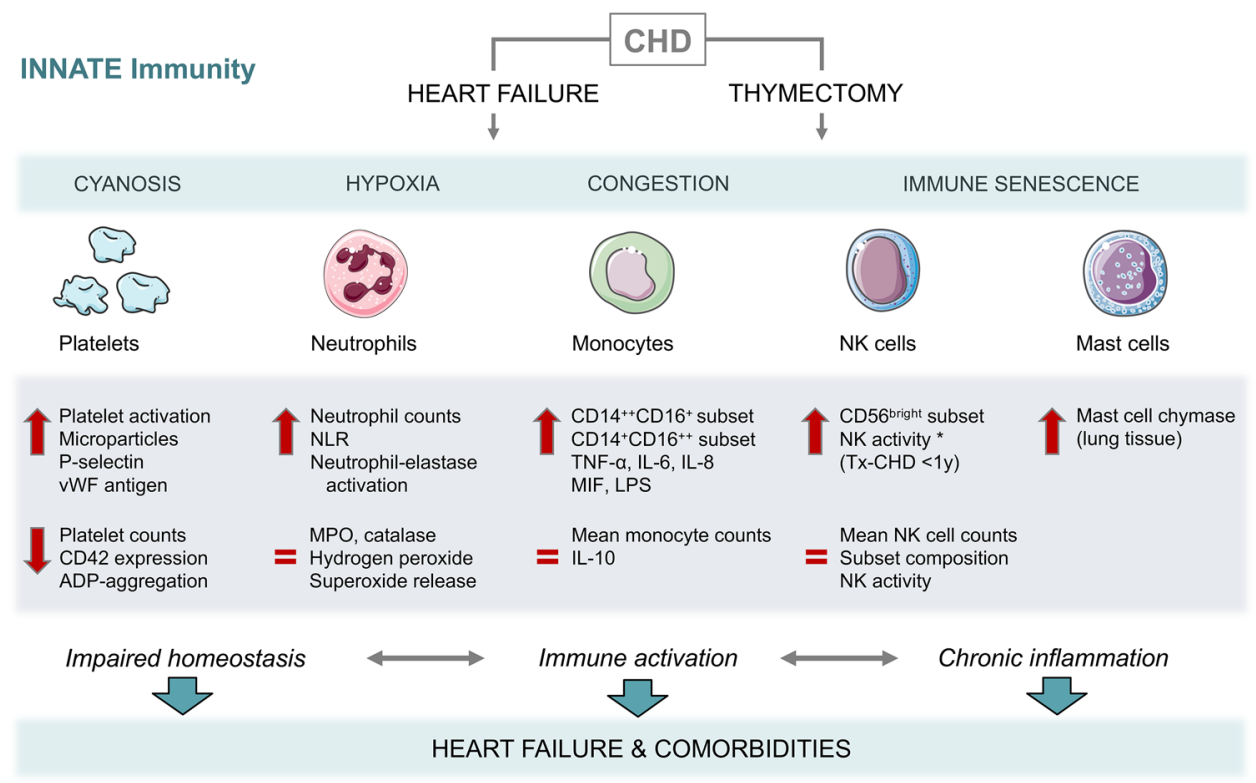

Fig. 1 Innate immune mediators. Congenital heart disease (CHD)associated heart failure and thymectomy are related to alterations of innate immune effectors contributing to impaired homeostasis, immune activation, and chronic inflammation. These changes can impair heart failure and promote comorbidities. Bold red flashes indicate increased or decreased parameters; equal sign indicates unchanged parameters in CHD compared to healthy controls. *Indicates increased NK cell activity only in CHD patients who had been thymectomized at the age of 1 year or younger. Servier Medical Art PowerPoint templates were used for graphical illustration. ADP adenosine diphosphate, $C D$ cluster of differentiation, $C H D$ congenital heart disease, $I L$ interleukin, $L P S$ lipopolysaccharide, $M I F$ macrophage migration inhibitory factor, $M P O$ myeloperoxidase, $N K$ natural killer cells, $N L R$ neutrophil-to-lymphocyte ratio, $T N F$ tumor necrosis factor, $T x$ thymectomized patients, $v W F$ Von Willebrand factor, $y$ year of life 


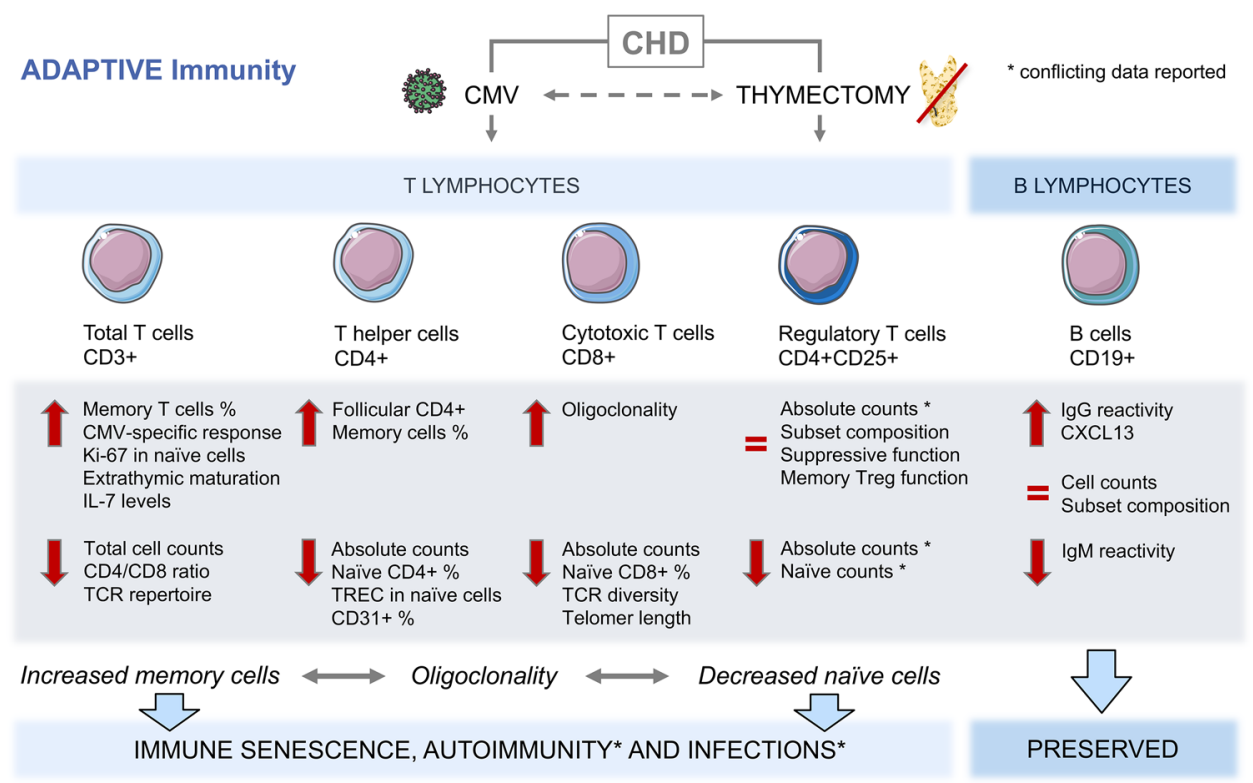

Fig. 2 Adaptive immune mediators. Congenital heart disease (CHD)associated early thymectomy and CMV seropositivity are related to alterations of adaptive immune effectors, such as increased memory and decreased naïve $\mathrm{T}$ cells and signs of oligoclonality. These changes are contributing to premature immune senescence and increased incidence of autoimmune diseases and other comorbidities. B cell compartments are not affected itself. Red flashes indicate increased or decreased parameters; equal sign indicates unchanged

present in patients with CHD and may result from infant thymectomy (Fig. 2). The detailed changes in innate and adaptive immunity are described below discussing possible parameters in CHD compared to controls. ${ }^{\%}$ Indicates proportional increase of the compartment. *Indicates conflicting data, discussed in the appropriate section of the text. Servier Medical Art PowerPoint templates were used for graphical illustration. $C D$ cluster of differentiation, $C H D$ congenital heart disease, $C M V$ cytomegalovirus, $I g$ immunoglobulin, $I L$ interleukin, TCR T cell receptor, TREC T cell receptor excision circles, Treg regulatory $\mathrm{T}$ cells

causes or contributing factors to CHD-HF, such as congestion, hypoxia, open-heart surgery, genetic syndromes, and comorbidities, as condensed in Fig. 3.

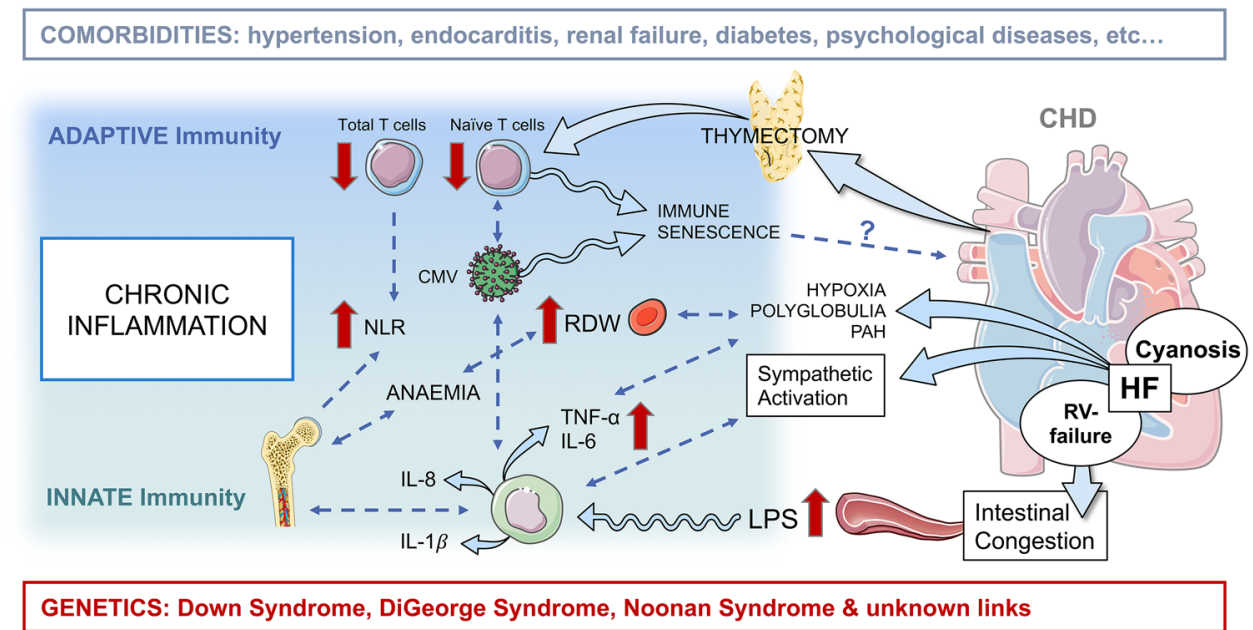

Fig. 3 Central illustration. Immunity and inflammation represent key players in heart failure and associated comorbidities in CHD. Thymectomy affects $\mathrm{T}$ cells of the adaptive immune system. Whereas heart failure-induced congestion, hypoxia and sympathetic activation can influence especially effectors of the innate immune system, such as monocytes, resulting in increased cytokine levels and immune activation. Servier Medical Art PowerPoint templates were used for graphical illustration. $C H D$ congenital heart disease, $C M V$ cytomegalovirus, $H F$ heart failure, $I L$ interleukin, $L P S$ lipopolysaccharide, $N L R$ neutrophil-to-lymphocyte ratio, $P A H$ pulmonary hypertension, $R D W$ red blood cell distribution width, $R V$ right ventricular, $T N F$ tumor necrosis factor 


\section{Heart failure, congestion, and hypoxia as immune stimulators in CHD}

The various hemodynamic conditions of severe CHD can activate the immune system by causing myocardial injury, hypoxia, edema, and hypoperfusion, contributing to chronic inflammation and the onset or progression of complicating comorbidities in CHD. The other way around, remote injury, and systemic inflammation can induce a local myocardial inflammatory response mediated by cardiac macrophages [10]. Thus, systemic inflammation and HF are mechanistically linked. A characteristic issue in some CHD is right ventricular dysfunction, which results in congestion as well as in peripheral and intestinal edema. Hypoperfusion and bowel wall edema facilitate bacterial lipopolysaccharide (LPS) translocation from the gut lumen into blood circulation [11-13]. Indeed, several studies found that blood bacterial endotoxin levels (e.g., LPS) related to HF characteristics and post-surgery outcome in CHD patients [13-15]. In adult patients with congenital heart disease (ACHD), elevated proinflammatory cytokines and bacterial endotoxins related to HF functional status and peripheral congestion [16]. Through stimulation of toll-like receptor (TLR)-expressing immune cells, such as monocytes, bacterial endotoxins can induce a significant cytokine production and inflammatory immune response, maintaining an inflammatory state. In addition, hypoxia represents a potential immune stimulus in CHD, since it is known that patients with cyanotic heart defects display particularly elevated TNF- $\alpha$, IL- 6 , and higher hsCRP [16-18]. Hypoxia itself induces the transcription of several inflammation-promoting genes, such as NF- $\mathrm{KB}$ and TLRs, via the alpha subunit of the hypoxia-inducible transcription factor (HIF-1 $\alpha$ ) [19]. In cyanotic children with CHD, myocardial induction of the inflammation-related IL-6-JAK-STAT and NF- $\mathrm{kB}$ pathways was demonstrated including increased IL-6, C-myc, and suppressor of cytokine signalling-3 (SOCS3) mRNA levels [20]. Hypoxia-induced SOCS3 expression can be stimulated by inflammation and infection and is involved in the myocardial adaptation to chronic hypoxia in CHD [20, 21]. Induction of SOCS3 was reported to be a promising treatment strategy in rodent acute inflammation models $[22,23]$. Thus, SOCS3 regulation in hypoxia and inflammation of CHD patients represents an interesting translational therapeutic target. Cyanosis and hypoxia are predominantly the result of some distinct cardiac malformations, such as shunt defects and Fontan circulation, sometimes complicated with pulmonary hypertension, Eisenmenger syndrome, and right heart failure. In infants with CHD, several inflammatory molecules, such as RANTES and macrophage migration inhibitory factor (MIF) related to pulmonary congestion or pulmonary vascular resistance, respectively-mechanisms known to be involved in the pathophysiology of pulmonary hypertension [24]. Therefore, hemodynamics of cardiac malformations and inflammatory pathways seem to impact each other in HF of CHD.

\section{Thymectomy relating to long-term adaptive immune alterations}

The majority of CHD patients underwent cardiac surgery during childhood with an increasing proportion of operated CHD in the last decades [25]. Surgical access for corrective or palliative operations often involves a sternotomy and incidental partial or complete removal of the thymus. However, the amount of eliminated tissue highly depends on the individual anatomy, surgeons, hospital standards, type of surgery, and patient age [26]. Thus, residual thymus size after early surgery varies between 0 and $50 \%$ of the initial mass, mainly caused by resting tissue of the upper poles [25, 27]. The thymus has its highest activity pre- and postnatally with a subsequent decrease during a person's lifespan as the organ physiologically involutes and degrades into fatty tissue [26]. Profound immune deficiency is known to result from complete thymus aplasia during fetal development, as caused by genetic syndromes, e.g., DiGeorge syndrome [ 9 , 28]. This raised the question about the long-term effects of incidental thymectomy due to open heart surgery in CHD. Despite the observed profound abnormalities of the $\mathrm{T}$ cell compartment and composition in early incidentally thymectomized CHD (Fig. 2, "17" section), several short-term studies have neither observed any clinically relevant immune deficiency nor elevated incidence of autoimmune diseases in comparison with age-matched controls [8, 29-32]. However, Halnon et al. investigated autoimmune events in CHD and found elevated anti-dsDNA levels and possibly a higher incidence of atopic skin reactions in children after early sternotomy [33]. The majority of the published studies are limited by the small numbers of cases and exhibited wide differences in age at and time since first open-heart surgery, which hinders an interpretation and comparison of the results. Considering the timepoint and the time passed since surgery is crucial in terms of the dynamic balance of T cell homeostatic pathways. An insufficient follow-up time might explain the various short-term studies failing to document a clinical impact of thymectomy in CHD. In contrast, the only large long-term investigation found several clinically relevant consequences of thymus removal. In this retrospective Swedish population-based cohort study, the authors investigated the incidence of autoimmune, infectious and atopic diseases as well as malignancies in CHD in relation to early thymectomy before the age of 5 years. Incidentally thymectomized patients had an increased risk for autoimmune diseases, hypothyroidism, and type 1 diabetes as well as for the occurrence of infections compared to a surgery control group receiving early 
cardiac surgery without thymectomy. Compared to a sexand age-matched general population, thymectomized CHD patients more frequently developed cancer, autoimmune diseases, and atopic diseases and had a markedly higher risk for relevant bacterial and viral infections (63.1 vs. 23.1\%) [25]. Complex and severe malformations generally require open-heart surgery more often and earlier in life. Hence, HF and thymectomy cannot be regarded strictly separately and might both play an important role in the observed immune alterations and comorbidities in CHD. Whether thymectomy and subsequent $\mathrm{T}$ cell alterations do in fact influence HF development or progression remains still unclear. As the discussed Swedish study results have not been confirmed elsewhere, further prospective clinical trials are needed to investigate the long-term consequences of total or partial thymectomy in CHD. Possible implications for the prevention and therapy of $\mathrm{T}$ cell deficiency and subsequent comorbidities as well as for the COVID-19 outcome will be discussed below.

\section{Genetic syndromes relating to CHD, inflammation, and immune alterations}

The most common genetic syndromes linked to congenital heart malformations are Down syndrome, DiGeorge syndrome, and Noonan syndrome. These have also been associated with immune deficiencies, senescence, and increased incidence of myelo- and lymphoproliferative malignancies. This raises the question about potential underlying links between cardiac and immune developmental biology. For instance, in coronary or heart valve development embryonic macrophages play a crucial role [34, 35]. However, the specific functions of macrophages or other immune cells in cardiac development and malformations are widely unknown.

\section{Down syndrome}

Down syndrome (DS, Trisomy 21) is associated with CHD, immune dysfunction, senescence, and precocious aging. About $40-50 \%$ of DS patients have congenital heart defects, mostly septal or atrioventricular canal defects [9]. DS comprises intrinsic immune alterations such as abnormalities in thymus size and structure as well as in T and B lymphocyte function [36]. This might be a central underlying factor contributing to the well-known high frequency of airway infections during youth and autoimmune disorders later in life, pointing to an immune dysregulation in DS [36].

\section{DiGeorge syndrome}

DiGeorge syndrome (22q11DS) is also related to congenital heart malformations and characterized by total or partial thymic aplasia resulting in an immunodeficiency and common clinical manifestations of recurrent infections and autoimmune diseases [37]. CHD can be found in 75-80\% of patients with DiGeorge syndrome representing a major cause of mortality [9]. Deficiencies of genes encoded in the deleted 22q11 region, such as TBX1 and CRKL have been found to be responsible for associated cardiovascular, renal, and thymic malformations [38]. Tbx1-deficient mice were characterized by developmental anomalies including thymic hypoplasia and cardiac outflow tract malformations [39]. Genes downstream of the transcription factor TBX1 during pharyngeal development are coding for the chemokine CXCL12 and its receptor CXCR4. Impaired CXCR4 signaling lead to malformations as seen in 22q11DS, suggesting an important role of the CXCL12/CXCR4 axis in its etiology [40].

\section{Noonan syndrome}

Noonan syndrome is characterized by various types of CHD or hypertrophic cardiomyopathy next to cognitive and growth restrictions as well as skeletal and hematological defects including an increased risk for leukemia [9]. Cytokine hierarchy was assumed to be related to the development of pathological LV hypertrophy as observed in a Raf1 mutant Noonan syndrome mouse model [41]. In this context, postnatal TNF inhibition normalized the existing hypertrophy in vivo suggesting TNF/IL-6 signaling as promising therapeutic targets in 8 caused by kinase-activating RAF1 mutations [41].

\section{Comorbidities relating to inflammation and immune alterations}

Chronic inflammation as well as immune alterations can be the causes and the consequences of comorbidities associated with CHD. Especially during early stages of HF, it has been suggested that inflammation represents a crucial common pathophysiological link between HF and other diseases [42]. A characteristic issue of CHD patients are clinically relevant thromboembolic events and altered hemostasis on the basis of abnormal hemodynamics, comorbidities, polycythaemia, impaired platelet number and function, influenced by inflammation and immune activation [43]. Furthermore, a high prevalence of relevant extra-cardiac comorbidities was noted in ACHD, affecting 95.2\% of patients [44]. In particular, the prevalence of various inflammation-related diseases, involving pulmonary, renal, metabolic or neurologic function, was several times higher in ACHD compared to the general population $[44,45]$. Directly caused by immunity, an elevated risk for certain autoimmune diseases, infections, cancer, and asthma has been detected in CHD [25]. Comorbidities were strongly associated with higher mortality and hospital admission rates, especially in aging ACHD [44]. In 
CHD-HF, inflammation could be a possible factor linking CHD-HF to these comorbidities but has not been focused on adequately in clinical routine for diagnostic and treatment purposes.

\section{Innate immunity in congenital heart disease}

The initial immune activation in HF is mainly driven by the innate immune system [42]. Innate immunity can be seen as the first line of defense including physical, chemical, cellular, and humoral barriers and protection strategies. Several insights have been gained regarding humoral and cellular immune activation in CHD (Fig. 1).

\section{Cytokines and chemokines}

The current literature regarding cytokines, chemokines, and parameters of systemic inflammation in CHD is summarized in Table 1 for children with CHD (CCHD) and Table 2 for ACHD. According to these insights, it can be stated that systemic inflammation is present in CHD and is associated with HF characteristics. Some studies illustrated that successful therapy of CHD-HF induced a normalization of inflammatory signaling and a decrease of blood cytokine levels [24, 46, 47]. In human whole heart tissue of CHD patients, an activation of the NF- $\mathrm{KB}$ pathway has been reported at comparable levels to non-congenital HF [48]. Thus, major inflammatory pathways seem to be activated in both entities of HF. However, on the whole, chemokines and their receptor expressions have not yet been extensively investigated in CHD. In children with CHD, elevated serum RANTES (CCL5) and MIF levels have been observed next to decreased angiogenic chemokine GRO $\alpha$ concentrations related to pulmonary impairment. Furthermore, elevated eotaxin plasma levels, a CC chemokine subfamily of eosinophil chemotactic proteins, have been revealed in young ACHD [14]. Further research regarding for example CXCR4 or fractalkine and its receptor CX3CR1 might be interesting, as they regulate monocyte recruitment, platelet activation, and inflammation in cardiovascular diseases.

\section{Neutrophils}

Neutrophils are produced and released by the bone marrow and represent the most abundant type of blood immune cells during the early innate immune response, acting towards host defense by degranulation, phagocytosis, and cell recruitment to the inflammation site. Higher blood neutrophil counts have been observed in CHD [29]. In addition, patients with cyanotic heart disease exhibited increased platelet activation next to elevated neutrophil elastase levels, a marker for neutrophil degranulation reflecting cell activation [49]. Several factors associated with hypoxia and HF might increase neutrophil activation, such as endothelial dysfunction, platelet activation, and inflammatory cytokines [49]. In terms of neutrophil function, no significant difference was found, indicating an intact neutrophilic innate immunity in CHD patients [50].

\section{Monocytes/macrophages}

Monocytes/macrophages represent powerful mediators of inflammation and innate immunity involved in cytokine production and cell recruitment. In HF and myocardial infarction, monocytes/macrophages play key roles in healing and remodeling, exhibiting both beneficial and detrimental functions $[5,51,52]$. This might be explained by the time course of activity and the existence of different monocyte and macrophage subtypes. In detail, three human monocyte subgroups have been described, $\mathrm{CD} 14^{++} \mathrm{CD} 16^{-}$(Mon1, classical), $\mathrm{CD} 14^{++} \mathrm{CD} 16^{+}$(Mon2, intermediate), and $\mathrm{CD} 14^{+} \mathrm{CD} 16^{++}$(Mon3, non-classical) monocytes, showing different phenotypic and functional characteristics [53]. We found Mon2 and Mon3, seen as rather proinflammatory monocytes, to be elevated and increasing with HF grade in ACHD outpatients. Highest Mon2 levels were observed in patients with native single ventricle, Eisenmenger syndrome and pulmonary hypertension-defects associated with severe congestion and cyanosis [54]. Further functional studies concentrating on monocytes and their role in CHD$\mathrm{HF}$ and risk stratification are still lacking.

\section{Natural killer cells}

Classified as innate lymphoid cells, natural killer (NK) cells can act immediately without specific antigen recognition to eliminate virus-infected or malignant cells. Hence, this cell lineage is essential for the body's anti-tumor strategies. NK cells are bone-marrow-derived and independent of $\mathrm{T}$ cell and thymus development as they do not undergo thymic maturation [55]. Accordingly, a number of studies did not find any differences in CHD NK cell number or composition, neither shortly nor years after thymectomy $[14,31,56]$. In contrast, in 1996, Ramos et al. reported an increased number of the CD16 ${ }^{-}$CD56 ${ }^{\text {bright }} \mathrm{NK}$ subset and a general increase of $\mathrm{NK}$ activity, but only in children who had been thymectomized during the first year of life. The authors suggest that the absence of the thymus promoted the differentiation of the common T and NK cell precursors into NK cells [57]. These conflicting data will need further investigation.

\section{Mast cells}

Mast cells are bone marrow-derived and play an important role in allergic reactions and parasite defense. An increased 


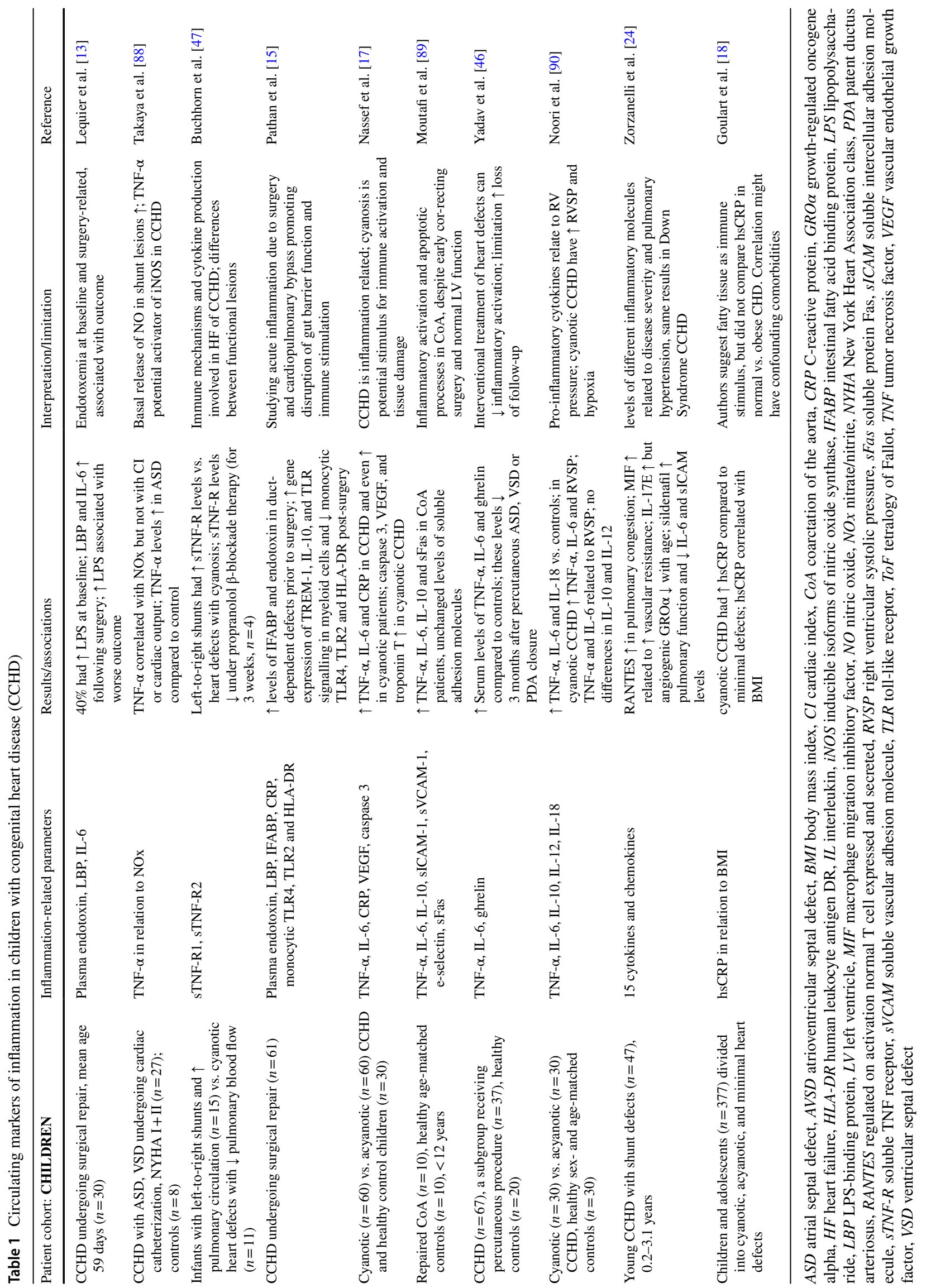




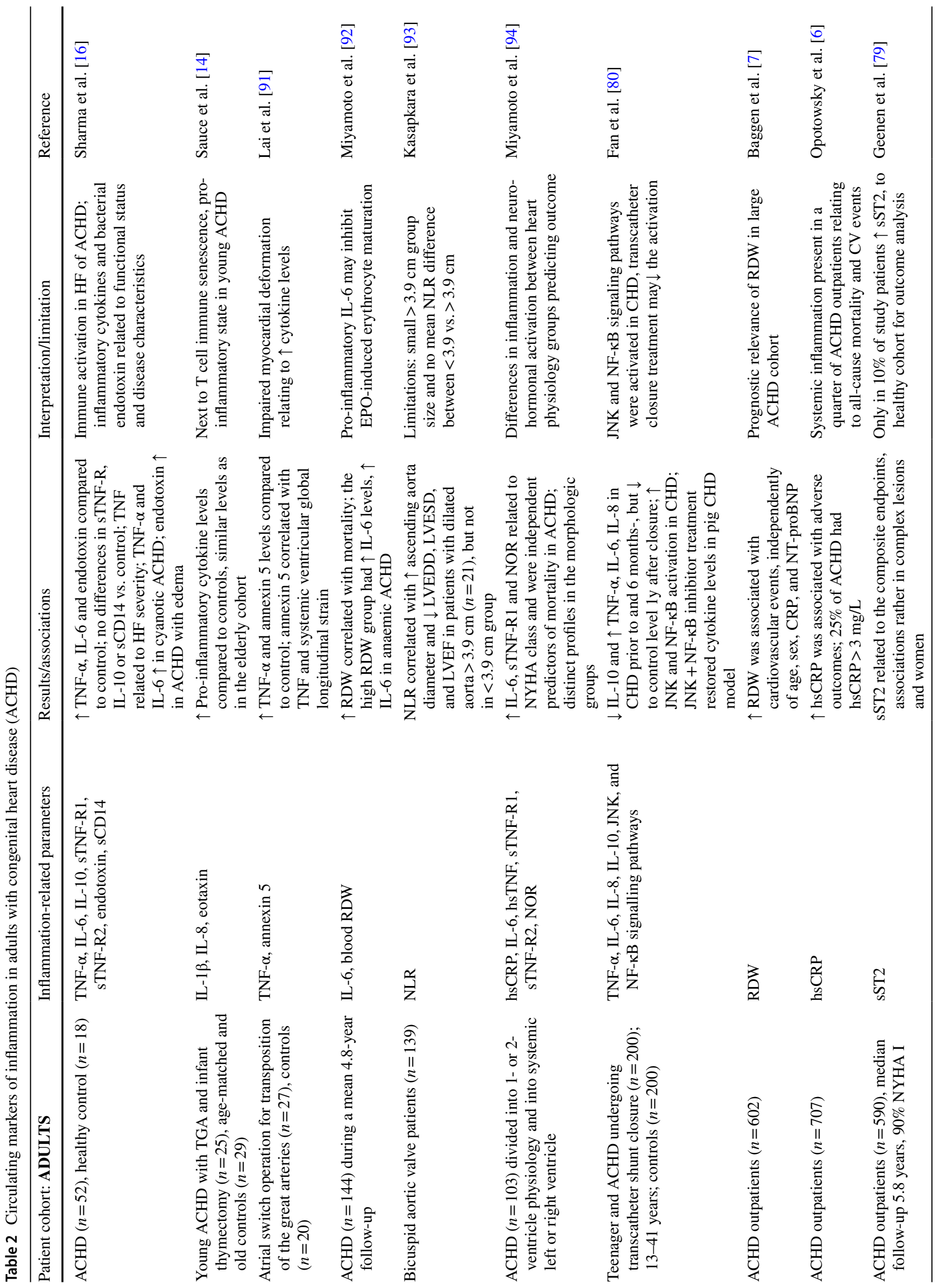




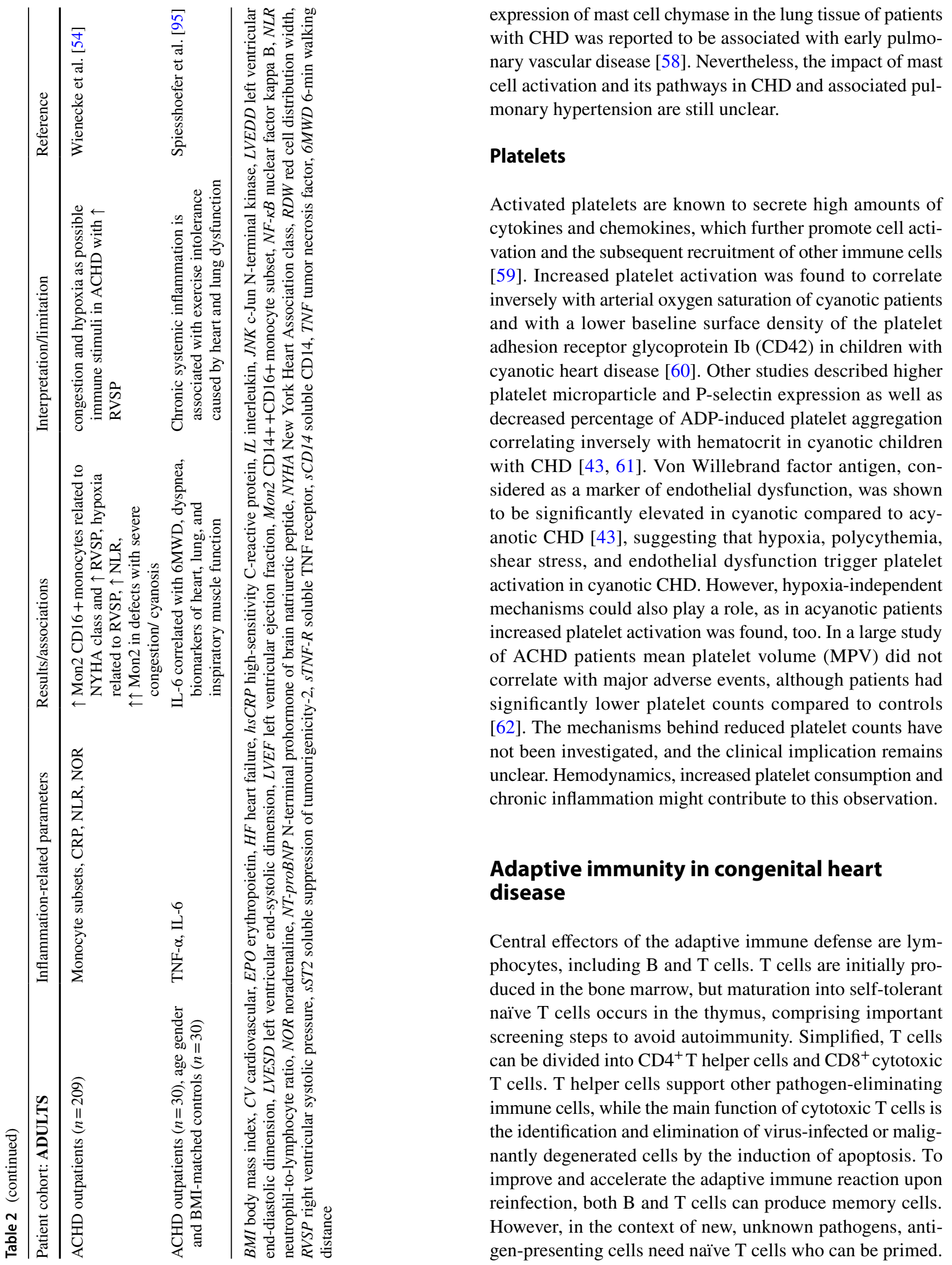


Therefore, the number of memory cells increases, and the number of naïve cells decreases during a person's lifespan due to pathogen contact and thymic involution [63, 64].

Adaptive (auto)immunity plays a crucial role in cardiac remodeling and heart failure progression. In various cardiovascular diseases, an activation, reactivation, or even persistence of the inflammatory cascade by the adaptive immune system has been shown including $\mathrm{T}$ cell activation, tissue infiltration, and expansion. Especially, the interplay between both adaptive and innate immune mediators gained much interest in cardiovascular research and bears broad therapeutic potential [63]. For instance, $\mathrm{CD} 4^{+} \mathrm{T}$ cells are involved in disease progression toward heart failure in murine models of hypertrophy or myocardial infarction $[63,65,66]$. T cell activation is suggested to occur in reaction to self-antigen presentation. In fact, recent insights show that myocardial injury is associated with anti-heart autoantibodies and characteristics of ongoing autoimmune responses [66, 67]. Activated $\mathrm{CD}^{+}{ }^{+} \mathrm{T}$ cells are known to further differentiate into distinct effector $T$ cell subsets $\left(T_{H} 1, T_{H} 2, T_{H} 17, T_{\text {reg, }}\right.$, etc.) having specific properties and functions during acute or chronic myocardial inflammation, e.g., cytokine production, $B$ cell activation, immunomodulation or endothelial cell activation [63]. The role of effector T cells in HF of CHD and the impact of thymectomy on auto-immune related processes upon myocardial injury represent emerging research topics, which have not been addressed scientifically, possibly due to lack of appropriate animal models. Described changes in adaptive immune mediators of incidentally thymectomized CHD patients are illustrated in Fig. 2.

\section{T helper and cytotoxic T cell compartments}

The thymus is the main source of T cells during youth and remains responsible for a low-level renewal of $\mathrm{T}$ cells up to the 6th decade of life. Hence, thymectomy especially during early stages of life can impair $\mathrm{T}$ cell production profoundly. Several studies revealed different abnormalities of the adaptive immune system in CHD patients who underwent thymectomy by open-heart surgery, already summarized by Roosen et al. [8]. We will add some new insights and highlight the main $\mathrm{T}$ cell variations related to infant sternotomy. In early thymectomized CHD, reduced total and especially naïve $\mathrm{CD} 4^{+} \mathrm{T}$ helper and $\mathrm{CD} 8^{+}$cytotoxic $\mathrm{T}$ cell compartments were reported, which persisted at least 2 decades after initial surgery $[14,31,56]$. Furthermore, these patients have a shorter $\mathrm{T}$ cell but unchanged $\mathrm{B}$ cell telomere length compared to controls and showed a diminished $\mathrm{T}$ cell receptor repertoire with signs of oligoclonality as well as augmented memory $\mathrm{T}$ cell levels $[32,56]$. These immune alterations are described as immune senescence and represent the reason for adaptive immune deficiency in the elderly general population [68]. Thymic tissue regeneration post-surgery might occur to a certain degree in some patients [69]. However, the alterations of immune cell composition can be directly linked to the amount of thymic tissue removed as patients with complete thymectomy had significantly lower or undetectable $\mathrm{T}$ cell recombination excision circles (TREC) levels, a marker for the extent of thymopoiesis, compared to those with residual thymus tissue [56, 70]. In thymectomized CHD, lower TREC levels of naïve $T$ cells and less recent thymic emigrants $\left(\mathrm{CD} 31^{+}\right)$in the helper $\mathrm{T}$ cell subset indicate a shift toward peripheral clonal expansion in order to compensate the lacking thymic output $[14,56,69,71,72]$. In addition, another study underlining the changes seen in $\mathrm{T}$ cell homeostasis described elevated plasma IL-7 levels and a negative correlation between absolute $\mathrm{CD} 4^{+} \mathrm{T}$ cells and IL-7 [31]. IL-7 is known to enhance thymopoiesis and to regulate the naïve $\mathrm{T}$ cell compartment. However, the maintenance of IL-7-induced homeostatic proliferation of naïve $\mathrm{T}$ cells requires a persistent thymic activity. The absence of thymic tissue might therefore impact $\mathrm{T}$ cell reconstitution and diversity throughout life [55, 73]. Loss of naïve T cells and consecutive accumulation of oligoclonal memory cells was also directly associated with cytomegalovirus (CMV) infections in thymectomized ACHD [14]. CMV infections can affect adaptive and innate immune mediators and play an important role in mechanisms of immune senescence. CMV is associated with increased mortality in the elderly and has been described as a promoter of cardiac diseases [74, 75]. CMV seroprevalence and its impact in CHD are unknown but deserve further research.

\section{Regulatory T cells}

Regulatory $\mathrm{T}$ cells (Treg) have increasingly gained attention as they are potent regulators of the immune system and exhibit strong immunosuppressive functions. Like other $\mathrm{T}$ cells, Tregs are released from the thymus as a naïve phenotype and generate a mature suppressor memory Treg compartment throughout life. Several groups measuring Treg subsets in thymectomized CHD patients reported conflicting data. Some investigations describe a preserved and unchanged Treg compartment [14, 33, 72, 76]. In contrast, during the first years after thymus removal, diminished total Treg counts were observed next to an increased proportion of activated and cytokine secreting Treg cells [77]. Eighteen years post-surgery, lower total and naïve Treg counts have been measured, but proportions of these cells as well as the Treg subset with highest suppressive potential $\left(\mathrm{CD}^{+} \mathrm{CD}^{4} 5 \mathrm{RA}^{-} \mathrm{CD} 25^{++}\right)$were unchanged [56]. Further conflicting data exist, regarding some reports about reduced naïve Tregs whereas others found unchanged counts but increased cell turnover [33, 56, 76, 77]. Differences are possibly due to varying patient selection, HF grade, residual thymus tissue, age at and time since surgery. Regarding Treg 
function, unchanged suppressive activity and expression levels of FoxP3, CTLA-4, and CD39, markers for the suppressive function phenotype, have been described within memory Tregs $[32,69]$. Of interest, the cytokine IL-7, elevated in thymectomized CHD plasma, is involved in the thymusindependent long-term maintenance and function of naïve Tregs [76], suggesting that IL-7-dependent homeostasis can sustain naïve Treg but not naïve $\mathrm{T}$ cell compartments. In conclusion, Tregs remain less affected than other $\mathrm{T}$ cells and might have normal, unchanged immunosuppressive functions.

\section{B cell compartments and function}

B cells need $\mathrm{T}$ cells for their complete functional capacity; however, maturation is independent of $\mathrm{T}$ cells or thymic tissue. Accordingly, the B cell counts, percentages and subset compositions were seen as unaffected in early thymectomized CHD by several reports [29, 31, 77]. Regarding B cell function, van den Broek and colleagues revealed decreased IgM autoantibodies and an increased IgG reactivity toward cardiolipin and leptin, suggesting a deranged self-tolerance. Follicular T helper cell counts as well as the production of the B lymphocyte chemoattractant (CXCL13) were increased. Furthermore, they reported a higher proportion of patients with positive antinuclear antibody (ANA) detection (58\% vs. $33 \%$ in healthy control). However, the authors did not observe an augmented onset of autoimmune diseases during the first decades of life but consider thymectomized CHD as a population at risk.

\section{Clinical implications of inflammation and immune alterations in CHD}

\section{Monitoring inflammation in clinical routine}

In several cardiovascular and non-cardiovascular diseases, biomarkers of inflammation exhibited prognostic relevance, due to the fact that inflammation and immune regulation are involved in respective disease mechanisms [78]. Accumulating evidence indicates an inflammatory state in some CHD. Recently, high-sensitivity C-reactive protein (hsCRP) was described as an independent predictor for cardiovascular events and all-cause mortality in ACHD. A quarter of all ACHD patients had elevated hsCRP, which was associated with worse functional capacity and markers of heart failure (HF) [6]. In addition, the neutrophil-to-lymphocyte ratio (NLR), suppression of tumorigenicity 2 (sST2), and red cell distribution width (RDW) were related to HF severity or outcome [7, 79]. Presumably, it may be helpful for clinical decision making to identify patients with relevant immune activation in the context of CHD-HF by assessing hsCRP and complete blood counts. Both can be measured easily in clinical or outpatient settings and represent cheap parameters in order to monitor inflammation and to add information for risk stratification. HF therapy success might also be reflected by changes in inflammatory markers. Interventional or drug treatments of $\mathrm{HF}$ lead to declining inflammatory cytokine levels in children with CHD and ACHD [46, 47, 80]. According to recent scientific findings, adaptive immune activation including circulating anti-heart autoantibodies might enable to monitor the immune response upon myocardial injury $[66,81]$. These autoantibodies represent an interesting potential biomarker in HF of CHD for detecting persistent, dysregulated adaptive immune activation [82]. Further research about underlying pathomechanisms and an evaluation of inflammation-guided HF therapy should be performed.

\section{Prevention and treatment of T cell deficiency}

Potential clinically relevant long-term consequences of early median sternotomy regarding $\mathrm{T}$ cell homeostasis have not been investigated sufficiently and need further research. In addition, the impact of the described immune alterations on cardiac remodeling and HF progression in CHD needs to be investigated. The degree of adaptive immune impairment in respective patients could be quantified by determining $\mathrm{T}$ cell compartments, markers of immune senescence or measuring TREC levels. To avoid a possible severe impairment of adaptive immunity, surgeons could attempt to preserve as much thymic tissue in situ as possible during open-heart surgery. Strategies evaluating a preparation of the operation field without explantation of the thymus or if necessary replantation of initially mobilized thymus tissue at the end of open-heart surgery might be of clinical interest. To protect physiological $\mathrm{T}$ cell production, primary percutaneous or minimally invasive procedures and lateral thoracotomy might be favored if possible. In patients with clinically relevant $\mathrm{T}$ cell deficiency, a future treatment option could target the inhibition of immune senescence and the induction of naïve $\mathrm{T}$ cell pool regeneration.

\section{Personalized immunomodulatory therapy}

CHD regroups several types and causes of cardiac defects, comorbidities, as well as different therapeutic interventions with or without thymectomy. As every CHD patient presents a very individual disease phenotype, the inflammatory immune profile and alterations might differ to a similar or even wider extent. Personalized immunomodulatory therapy could create a novel treatment option and strategy in CHD-HF. Immunomodulation is a therapeutic approach that recently entered clinical cardiology (CANTOS-trial) but was already used for years in the treatment of autoimmune 
and inflammatory diseases. Characterizing patients with significant inflammatory activation or immune deficiencies and identifying particular anti-inflammatory or "antiimmune senescence" therapeutic targets for different CHD immune-phenotypes might be a promising step towards a ground-breaking treatment strategy in CHD-HF to improve morbidity and mortality.

\section{Implications regarding severe COVID-19}

Immune changes and inflammation need to be kept in mind regarding the COVID-19 pandemic but have not been considered in recent reports [83]. T cell deficiency and immune senescence could potentially impair the organism's defense strategies and inflammatory response regulation. Indeed, $\mathrm{T}$ cell senescence and chronic inflammation have been considered a major cause for the well-known worse outcome after SARS-CoV2 infection in the elderly [84, 85]. Thus, $\mathrm{CHD}$ could be seen as a population at particular risk. However, it remains totally unclear whether the diminished naïve $\mathrm{T}$ cell pool in early thymectomized CHD patients might increase their susceptibility to SARS-CoV-2 infections or even lead to a poorer response to respective vaccines [86]. Linked to CHD and immune senescence, Down syndrome patients seem to develop a more severe form of the disease and have a worse outcome upon COVID-19 [87]. In order to investigate risk and outcome, the International Society for Adult Congenital Heart Disease built up a database of ACHD patients who have tested positive for SARS-CoV-2. When considering this, $T$ cell alterations and immune senescence, caused by early open-heart surgery, genetic syndromes or $\mathrm{HF}$, should be taken into account to allow interpretation of future study results.

\section{Conclusions}

Congenital heart disease displays several features of a chronic inflammatory disease and often involves significant immune activation and dysfunction of some lymphocyte subsets that should be considered, especially in the context of the current COVID-19 pandemic and the onset of extracardiac comorbidities. It is crucial that cardiologists, pediatric cardiologists and cardiothoracic surgeons are aware of the described immune changes and their potential implications. The still practiced surgery-related removal of thymic tissue should be questioned and further long-term investigations regarding the consequences of thymectomy initiated.

Acknowledgements The authors kindly thank Filip Swirski, Matthias Nahrendorf, Johanna Egelkamp, and Anna-Kristina Klüver for advice and critical review of the manuscript.
Author contribution Drs. Laura M. Wienecke and Benjamin G. Chousterman had the idea for the article; Dr. Laura M. Wienecke performed the literature search and drafted the manuscript; Drs. Sarah Cohen, Johann Bauersachs, Alexandre Mebazaa, and Benjamin G. Chousterman guided and critically revised the work.

Funding Open Access funding enabled and organized by Projekt DEAL. LMW received funding from the German Heart Foundation (Deutsche Herzstiftung e.V.) and an ERASMUS + Traineeship Grant.

Availability of data and material Not applicable.

Code availability Not applicable.

\section{Declarations}

Ethics approval The manuscript does not contain clinical studies or patient data.

Consent to participate Not applicable.

Consent for publication Not applicable.

Conflict of interest The authors declare no competing interests.

Open Access This article is licensed under a Creative Commons Attribution 4.0 International License, which permits use, sharing, adaptation, distribution and reproduction in any medium or format, as long as you give appropriate credit to the original author(s) and the source, provide a link to the Creative Commons licence, and indicate if changes were made. The images or other third party material in this article are included in the article's Creative Commons licence, unless indicated otherwise in a credit line to the material. If material is not included in the article's Creative Commons licence and your intended use is not permitted by statutory regulation or exceeds the permitted use, you will need to obtain permission directly from the copyright holder. To view a copy of this licence, visit http://creativecommons.org/licenses/by/4.0/.

\section{References}

1. Webb G, Mulder BJ, Aboulhosn J et al (2015) The care of adults with congenital heart disease across the globe: current assessment and future perspective: A position statement from the International Society for Adult Congenital Heart Disease (ISACHD). Int J Cardiol 195:326-333. https://doi.org/10.1016/j.ijcard.2015.04.230

2. Diller GP, Kempny A, Alonso-Gonzalez R et al (2015) Survival prospects and circumstances of death in contemporary adult congenital heart disease patients under follow-up at a large tertiary centre. Circulation 132:2118-2125. https://doi.org/10.1161/ CIRCULATIONAHA.115.017202

3. Engelings CC, Helm PC, Abdul-Khaliq H et al (2016) Cause of death in adults with congenital heart disease - an analysis of the German National Register for Congenital Heart Defects. Int J Cardiol 211:31-36. https://doi.org/10.1016/j.ijcard.2016.02.133

4. Stout KK, Broberg CS, Book WM et al (2016) Chronic Heart Failure in Congenital Heart Disease: A Scientific Statement From the American Heart Association. Circulation 133:770-801. https:// doi.org/10.1161/CIR.0000000000000352 
5. Swirski FK, Nahrendorf M (2013) Leukocyte behavior in atherosclerosis, myocardial infarction, and heart failure. Science 339:161-166. https://doi.org/10.1126/science.1230719

6. Opotowsky AR, Valente AM, Alshawabkeh L et al (2018) Congenital heart disease Prospective cohort study of C-reactive protein as a predictor of clinical events in adults with congenital heart disease : results of the Boston adult congenital heart disease biobank. Eur Heart J 39:3253-3261. https://doi.org/10.1093/eurheartj/ehy362

7. Baggen VJM, van den Bosch AE, van Kimmenade RR et al (2018) Red cell distribution width in adults with congenital heart disease: A worldwide available and low-cost predictor of cardiovascular events. Int J Cardiol 260:60-65. https://doi.org/10.1016/J. IJCARD.2018.02.118

8. Roosen J, Oosterlinck W, Meyns B (2015) Routine thymectomy in congenital cardiac surgery changes adaptive immunity without clinical relevance. Interact Cardiovasc Thorac Surg 20:101-106. https://doi.org/10.1093/icvts/ivu343

9. Calcagni G, Unolt M, Digilio MC et al (2017) Congenital heart disease and genetic syndromes : new insights into molecular mechanisms. Expert Rev Mol Diagn 17:861-870. https://doi.org/ 10.1080/14737159.2017.1360766

10. Hoyer FF, Naxerova K, Schloss MJ et al (2019) Tissue-specific macrophage responses to remote injury impact the outcome of subsequent local immune challenge. Immunity 51:899-914.e7. https://doi.org/10.1016/j.immuni.2019.10.010

11. Anker SD, von Haehling S (2004) Inflammatory mediators in chronic heart failure: an overview. Heart 90:464-470. https://doi. org/10.1136/hrt.2002.007005

12. Valentova $\mathbf{M}$, von Haehling $S$, Bauditz $\mathbf{J}$ et al (2016) Intestinal congestion and right ventricular dysfunction: a link with appetite loss, inflammation, and cachexia in chronic heart failure. Eur Heart J 37:1684-1691. https://doi.org/10.1093/eurheartj/ehw008

13. Lequier LL, Nikaidoh H, Leonard SR et al (2000) Preoperative and postoperative endotoxemia in children with congenital heart disease. Chest 117:1706-1712. https://doi.org/10.1378/chest. 117.6.1706

14. Sauce D, Larsen M, Fastenackels S et al (2009) Evidence of premature immune aging in patients thymectomized during early childhood. J Clin Invest 119:3070-3078. https://doi.org/10.1172/ JCI39269

15. Pathan $N$, Burmester $M$, Adamovic $T$ et al (2011) Intestinal injury and endotoxemia in children undergoing surgery for congenital heart disease. Am J Respir Crit Care Med 184:1261-1269. https:// doi.org/10.1164/rccm.201104-0715OC

16. Sharma R, Bolger AP, Li W et al (2003) Elevated circulating levels of inflammatory cytokines and bacterial endotoxin in adults with congenital heart disease. Am J Cardiol 92:188-193. https:// doi.org/10.1016/S0002-9149(03)00536-8

17. Nassef YE, Hamed MA, Aly HF (2013) Inflammatory Cytokines, Apoptotic, Tissue Injury and Remodeling Biomarkers in Children with Congenital Heart Disease. Ind J Clin Biochem 29:145-149. https://doi.org/10.1007/s12291-013-0341-0

18. Goulart MR, Schneid Schuh D, Moraes DWM et al (2017) Serum C-reactive protein levels and body mass index in children and adolescents with CHD. Cardiol Young 27:1083-1089. https://doi. org/10.1017/S1047951116002080

19. Eltzschig HK, Carmeliet $P$ (2011) Hypoxia and Inflammation. $\mathrm{N}$ Engl J Med 364:656-665. https://doi.org/10.1056/NEJMra0910283

20. Gu Q, Kong Y, Yu Z et al (2011) Hypoxia-induced SOCS3 is limiting STAT3 phosphorylation and NF- $\mathrm{k}$ B activation in congenital heart disease. Biochimie 93:909-920. https://doi.org/10.1016/j. biochi.2011.02.009

21. Carow B, Rottenberg ME (2014) SOCS3, a major regulator of infection and inflammation. Front Immunol 5:1-13. https://doi. org/10.3389/fimmu.2014.00058
22. Jo D, Liu D, Yao S et al (2005) Intracellular protein therapy with SOCS3 inhibits inflammation and apoptosis. Nat Med 11:892898. https://doi.org/10.1038/nm1269

23. Shouda T, Yoshida $T$, Hanada $T$ et al (2001) Induction of the cytokine signal regulator SOCS3/CIS3 as a therapeutic strategy for treating inflammatory arthritis. J Clin Invest 108:1781-1788. https://doi.org/10.1172/JCI200113568

24. Zorzanelli L, Maeda N, Clavé M et al (2017) Relation of cytokine profile to clinical and hemodynamic features in young patients with congenital heart disease and pulmonary hypertension. Am J Cardiol 119:119-125. https://doi.org/10.1016/j.amjcard.2016.09.020

25. Gudmundsdottir J, Söderling J, Berggren $\mathrm{H}$ et al (2018) Long-term clinical effects of early thymectomy: Associations with autoimmune diseases, cancer, infections, and atopic diseases. J Allergy Clin Immunol 141:2294-2297.e8. https://doi.org/10.1016/j.jaci. 2018.01.037

26. Elder RW, George RP, McCabe NM et al (2015) Immunologic aging in adults with congenital heart disease: does infant sternotomy matter? Pediatr Cardiol 36:1411-1416. https://doi.org/ 10.1007/s00246-015-1174-9

27. Brearley S, Gentle TA, Baynham D et al (1987) Immunodeficiency following neonatal thymectomy in man. Clin Exp Immunol 70:322-327

28. Piliero LM, Sanford AN, Mcdonald-mcginn DM et al (2016) T-cell homeostasis in humans with thymic hypoplasia due to chromosome 22q11. 2 deletion syndrome. Blood 103:1020-1026. https://doi.org/10.1182/blood-2003-08-2824

29. Eysteinsdottir JH, Freysdottir J, Haraldsson A et al (2004) The influence of partial or total thymectomy during open heart surgery in infants on the immune function later in life. Clin Exp Immunol 136:349-355. https://doi.org/10.1111/j.1365-2249.2004.02437.x

30. Wells WJ, Parkman R, Smogorzewska E, Barr M (1998) Neonatal thymectomy: does it affect immune function? J Thorac Cardiovasc Surg 115:1041-1046. https://doi.org/10.1016/S0022-5223(98) 70403-9

31. Mancebo E, Clemente J, Sanchez J et al (2008) Longitudinal analysis of immune function in the first 3 years of life in thymectomized neonates during cardiac surgery. Clin Exp Immunol 154:375-383. https://doi.org/10.1111/j.1365-2249.2008.03771.x

32. Silva SL, Albuquerque A, Amaral AJ et al (2017) Autoimmunity and allergy control in adults submitted to complete thymectomy early in infancy. PLoS ONE 12:1-13. https://doi.org/10.1371/ journal.pone.0180385

33. Halnon NJ, Cooper P, Yu D et al (2011) Immune dysregulation after cardiothoracic surgery and incidental thymectomy: maintenance of regulatory $\mathrm{T}$ cells despite impaired thymopoiesis. Clin Dev Immunol 2011:915864. https://doi.org/10.1155/2011/915864

34. Leid J, Carrelha J, Boukarabila H et al (2016) Primitive embryonic macrophages are required for coronary development and maturation. Circ Res 118:1498-1511. https://doi.org/10.1161/CIRCRESAHA. 115.308270

35. Kim AJ, Xu N, Yutzey KE (2021) Macrophage lineages in heart valve development and disease. Cardiovasc Res 117:663-673. https://doi.org/10.1093/cvr/cvaa062

36. Kusters MAA, Verstegen RHJ, Gemen EFA, De VE (2009) Intrinsic defect of the immune system in children with Down syndrome : a review. Clin Exp Immunol 156:189-193. https:// doi.org/10.1111/j.1365-2249.2009.03890.x

37. Jawad AF, McDonald-McGinn DM, Zackai E, Sullivan KE (2001) Immunologic features of chromosome 22q11.2 deletion syndrome (DiGeorge syndrome / velocardiofacial syndrome). J Pediatr 139:715-723. https://doi.org/10.1067/mpd.2001.118534

38. Merscher S, Funke B, Epstein JA et al (2001) TBX1 is responsible for cardiovascular defects in velo-cardio-facial/DiGeorge syndrome. Cell 104:619-629. https://doi.org/10.1016/S0092-8674(01)00247-1 
39. Jerome LA, Papaioannou VE (2001) DiGeorge syndrome phenotype in mice mutant for the T-box gene, Tbx1. Nat Genet 27:286291. https://doi.org/10.1038/85845

40. Duband J, Escot S, Fournier-thibault C (2016) SDF1-CXCR4 signaling: a new player involved in DiGeorge / 22q11-deletion syndrome. Rare Dis 4:1-8. https://doi.org/10.1080/21675511. 2016.1195050

41. Yin JC, Platt MJ, Tian X et al (2017) Cellular interplay via cytokine hierarchy causes pathological cardiac hypertrophy in RAF1-mutant Noonan syndrome. Nat Commun 8:1-11. https:// doi.org/10.1038/ncomms 15518

42. Frantz S (2017) Heart failure as a systemic disease: role of inflammation. J Pediatr Cardiol Card Surg 1:42-44. https://doi.org/10. 24509/jpccs. 170108

43. Ismail EAR, Youssef OI (2013) Platelet-derived microparticles and platelet function profile in children with congenital heart disease. Clin Appl Thromb 19:424-432. https://doi.org/10. $1177 / 1076029612456733$

44. Neidenbach RC, Lummert E, Vigl M et al (2018) Non-cardiac comorbidities in adults with inherited and congenital heart disease: report from a single center experience of more than 800 consecutive patients. Cardiovasc Diagnosis Ther 8:423-431. https://doi.org/10.21037/cdt.2018.03.11

45. Dimopoulos K, Diller G-P, Koltsida E et al (2008) Prevalence, predictors, and prognostic value of renal dysfunction in adults with congenital heart disease. Circulation 117:2320-2328. https://doi.org/10.1161/CIRCULATIONAHA.107.734921

46. Yadav SK, Yi Q (2015) Changes in serum level of ghrelin, tumor necrosis factor- $\alpha$ and interleukin-6 in children with congenital heart disease. Asian J Med Sci 6:12-16. https://doi.org/ 10.3126/ajms.v6i5.12129

47. Buchhorn R, Wessel A, Hulpke-Wette M et al (2001) Endogenous nitric oxide and soluble tumor necrosis factor receptor levels are enhanced in infants with congenital heart disease. Crit Care Med 29:2208-2210

48. Mou SS, Haudek SB, Lequier L et al (2002) Myocardial inflammatory activation in children with congenital heart disease. Crit Care Med 30:827-832. https://doi.org/10.1097/00003246-200204000-00018

49. McLeod KA, Martin P, Williams G, Walker DR (1994) Neutrophil activation and morbidity in young adults with cyanotic congenital heart disease. Blood Coagul Fibrinolysis 5:17-22. https://doi.org/ 10.1097/00001721-199402000-00003

50. Akinci O, Mihci E, Tacoy S et al (2010) Neutrophil oxidative metabolism in down syndrome patients with congenital heart defects. Environ Mol Mutagen 51:57-63. https://doi.org/10.1002/em.20511

51. Nahrendorf M, Swirski FK, Aikawa E et al (2007) The healing myocardium sequentially mobilizes two monocyte subsets with divergent and complementary functions. J Exp Med 204:30373047. https://doi.org/10.1084/jem.20070885

52. Fraccarollo D, Thomas S, Scholz CJ et al (2019) Macrophage mineralocorticoid receptor is a pleiotropic modulator of myocardial infarct healing. Hypertension 73:102-111. https://doi.org/10. 1161/HYPERTENSIONAHA.118.12162

53. Ziegler-Heitbrock L, Ancuta P, Crowe $S$ et al (2010) Nomenclature of monocytes and dendritic cells in blood. Blood 116:5-7. https://doi.org/10.1182/blood-2010-02-258558

54. Wienecke LM, Fraccarollo D, Galuppo P et al (2019) Pro-inflammatory intermediate monocytes relate to right ventricular pressure in heart failure of adult congenital heart disease. Eur Heart J 40. https://doi.org/10. 1093/eurheartj/ehz746.0899

55. Williams KM, Hakim FT, Gress RE (2007) T cell immune reconstitution following lymphodepletion. Semin Immunol 19:318-330. https://doi.org/10.1016/j.smim.2007.10.004

56. Gudmundsdottir J, Óskarsdóttir S, Skogberg G et al (2016) Early thymectomy leads to premature immunologic ageing: an 18-year follow-up. J Allergy Clin Immunol 138:1439-1443.e10. https:// doi.org/10.1016/j.jaci.2016.05.014

57. Ramos SBV, Garcia AB, Vianna SR et al (1996) Phenotypic and functional evaluation of natural killer cells in thymectomized children. Clin Immunol Immunopathol 81:277-281. https://doi.org/ 10.1006/clin.1996.0189

58. Hamada H, Terai M, Kimura $H$ et al (1999) Increased expression of mast cell chymase in the lungs of patients with congenital heart disease associated with early pulmonary vascular disease. Am J Respir Crit Care Med 160:1303-1308. https://doi.org/10.1164/ ajrccm.160.4.9810058

59. Flierl U, Bauersachs J, Schäfer A (2015) Modulation of platelet and monocyte function by the chemokine fractalkine (CX3CL1) in cardiovascular disease. Eur J Clin Invest 45:624-634. https:// doi.org/10.1111/eci.12443

60. Olgun N, Uysal KM, Irken G et al (1997) Platelet activation in congenital heart diseases. Pediatr Int 39:566-569. https://doi.org/ 10.1111/j.1442-200X.1997.tb03642.x

61. Horigome H, Hiramatsu Y, Shigeta O et al (2002) Overproduction of platelet microparticles in cyanotic congenital heart disease with polycythemia. J Am Coll Cardiol 39:1072-1077. https://doi.org/ 10.1016/S0735-1097(02)01718-7

62. De GLP, Canaria PDG, Palmas L et al (2019) Mean platelet volume and major adverse cardiovascular events in congenital heart disease patients. Clin Hemorheol Microcirc 72:327-337. https:// doi.org/10.3233/CH-180471

63. Adamo L, Rocha-Resende C, Prabhu SD, Mann DL (2020) Reappraising the role of inflammation in heart failure. Nat Rev Cardiol 17:269-285. https://doi.org/10.1038/s41569-019-0315-x

64. Appel M, Frantz S, Campos Ramos G (2021) Myocardial inflammation comes of age. Curr Opin Physiol 19:47-54. https://doi.org/ 10.1016/j.cophys.2020.09.006

65. Laroumanie F, Douin-Echinard V, Pozzo J et al (2014) CD4+ T cells promote the transition from hypertrophy to heart failure during chronic pressure overload. Circulation 129:2111-2124. https:// doi.org/10.1161/CIRCULATIONAHA.113.007101

66. Forte E, Panahi M, Baxan N et al (2021) Type 2 MI induced by a single high dose of isoproterenol in C57BL / $6 \mathrm{~J}$ mice triggers a persistent adaptive immune response against the heart. J Mol Cell Cardiol 25:229-243. https://doi.org/10.1111/jcmm.15937

67. Sintou A, Mansfield C, Iacob A et al (2020) Mediastinal lymphadenopathy, class-switched auto-antibodies and myocardial immunecomplexes during heart failure in rodents and humans. Front Cell Dev Biol 8:1-12. https://doi.org/10.3389/fcell.2020.00695

68. Hakim FT, Gress RE (2007) Immunosenescence: deficits in adaptive immunity in the elderly. Tissue Antigens 70:179-189. https:// doi.org/10.1111/j.1399-0039.2007.00891.x

69. Van Den BT, Jansen NJG, Van F et al (2016) Neonatal thymectomy reveals differentiation and plasticity within human naive $\mathrm{T}$ cells. J Clin Invest 126:1126-1136. https://doi.org/10.1172/JCI84997. Introduction

70. Halnon NJ, Jamieson B, Plunkett M et al (2005) Thymic function and impaired maintenance of peripheral $\mathrm{T}$ cell populations in children with congenital heart disease and surgical thymectomy. Pediatr Res 57:42-48. https://doi.org/10.1203/01.PDR.0000147735.19342.DE

71. Prelog M, Keller M, Geiger R et al (2009) Thymectomy in early childhood: Significant alterations of the CD4+CD45RA+CD62L+ $\mathrm{T}$ cell compartment in later life. Clin Immunol 130:123-132. https://doi.org/10.1016/j.clim.2008.08.023

72. Torfadottir H, Freysdottir J, Skaftadottir I et al (2006) Evidence for extrathymic $\mathrm{T}$ cell maturation after thymectomy in infancy. Clin Exp Immunol 145:407-412. https://doi.org/10.1111/j.13652249.2006.03139.x

73. Silva SL, Albuquerque AS, Matoso P (2017) IL-7-induced proliferation of human naive CD4 T-cells relies on continued thymic 
activity. Front Immunol 8:20. https://doi.org/10.3389/fimmu.2017. 00020

74. Pawelec G, Derhovanessian E (2011) Role of CMV in immune senescence. Virus Res 157:175-179. https://doi.org/10.1016/j. virusres.2010.09.010

75. Nilsson B, Wikby A, Johansson B et al (2002) Expansions of peripheral blood CD8 T-lymphocyte subpopulations and an association with cytomegalovirus seropositivity in the elderly : the Swedish NONA immune study. Exp Gerontol 37:445-453. https:// doi.org/10.1016/s0531-5565(01)00212-1

76. Silva SL, Albuquerque AS, Serra-caetano A et al (2016) Human naïve regulatory T-cells feature high steady-state turnover and are maintained by IL-7. Oncotarget 7:12163-12175. https://doi.org/ 10.18632/oncotarget.7512

77. Van Den BT, Madi A, Delemarre EM et al (2017) Human neonatal thymectomy induces altered B-cell responses and autoreactivity. Eur J Immunol 47:1970-1981. https://doi.org/10.1002/eji.201746971

78. Braunwald E (2008) Biomarkers in heart failure. N Engl J Med 358:2148-2159. https://doi.org/10.1056/NEJMra0800239

79. Geenen LW, Baggen VJM, Van Den Bosch AE et al (2019) Prognostic value of soluble ST2 in adults with congenital heart disease. Heart 105:999-1006. https://doi.org/10.1136/heartjnl-2018-314168

80. Fan S, Li K, Zhang D, Liu F (2017) JNK and NF- $\kappa B$ signaling pathways are involved in cytokine changes in patients with congenital heart disease prior to and after transcatheter closure. Exp Ther Med 15:1525-1531. https://doi.org/10.3892/etm.2017.5595

81. Morbach C, Beyersdorf N, Kerkau T et al (2021) Adaptive antimyocardial immune response following hospitalization for acute heart failure. ESC Hear Fail 8:3348-3353. https://doi.org/10. 1002/ehf2.13376

82. Leuschner F, Li J, Göser S et al (2008) Absence of auto-antibodies against cardiac troponin I predicts improvement of left ventricular function after acute myocardial infarction. Eur Heart J 29:19491955. https://doi.org/10.1093/eurheartj/ehn268

83. Alsaied T, Aboulhosn JA, Cotts TB et al (2020) Coronavirus disease 2019 (COVID-19) pandemic implications in pediatric and adult congenital heart disease. J Am Heart Assoc 9:e017224. https://doi.org/10.1161/JAHA.120.017224

84. Akbar AN, Gilroy DW (2020) Aging immunity may exacerbate COVID-19. Science 369:256-257. https://doi.org/10.1126/science. abb0762

85. Omarjee L, Janin A, Perrot F et al (2020) Targeting T-cell senescence and cytokine storm with rapamycin to prevent severe progression in COVID-19. Clin Immunol 216. https://doi.org/10. 1016/j.clim.2020.108464
86. Čičin-Šain L, Smyk-Paerson S, Currier N et al (2010) Loss of naive $\mathrm{T}$ cells and repertoire constriction predict poor response to vaccination in old primates. J Immunol 184:6739-6745. https:// doi.org/10.4049/jimmunol.0904193

87. Malle L, Gao C, Hur C et al (2020) Individuals with Down syndrome hospitalized with COVID-19 have more severe disease. Genet Med 1-5. https://doi.org/10.1038/s41436-020-01004-w

88. Takaya J, Ikemoto Y, Teraguchi M et al (2000) Plasma nitric oxide products correlate with cardiac index of congenital heart disease. Pediatr Cardiol 21:378-381. https://doi.org/10.1007/s002460010086

89. Moutafi AC, Alissafi T, Chamakou A et al (2012) Neurohormonal activity and vascular properties late after aortic coarctation repair. Int J Cardiol 159:211-216. https://doi.org/10.1016/j.ijcard.2011. 02.071

90. Noori NM, Shahramian I, Teimouri A et al (2017) Serum levels of tumor necrosis factor- $\alpha$ and interleukins in children with congenital heart disease. J Teh Univ Hear Ctr 12:15-22. PMC5409944

91. Lai CTM, Chow P, Wong SJ et al (2012) Circulating annexin A5 levels after atrial switch for transposition of the great arteries : relationship with ventricular deformation and geometry. PLoS One 7. https://doi.org/10.1371/journal.pone.0052125

92. Miyamoto K, Inai K, Takeuchi D et al (2015) Relationships among red cell distribution width, anemia, and interleukin-6 in adult congenital heart disease. Circ J 79:1100-1106. https://doi. org/10.1253/circj.CJ-14-1296

93. Kasapkara HA, Aslan AN, Ayhan H, Güney MC (2016) Higher neutrophil to lymphocyte ratio is related to a lower ejection fraction in bicuspid aortic valve patients. 1144-1150. https://doi.org/ 10.3906/sag-1508-4

94. Miyamoto K, Takeuchi D, Inai K et al (2016) Prognostic value of multiple biomarkers for cardiovascular mortality in adult congenital heart disease: comparisons of single-/two-ventricle physiology, and systemic morphologically right/left ventricles. Heart Vessels 31:1834-1847. https://doi.org/10.1007/s00380-016-0807-0

95. Spiesshoefer J, Orwat S, Henke C et al (2020) Inspiratory muscle dysfunction and restrictive lung function impairment in congenital heart disease: association with immune inflammatory response and exercise intolerance. Int J Cardiol 318:45-51. https://doi.org/ 10.1016/j.ijcard.2020.06.055

Publisher's Note Springer Nature remains neutral with regard to jurisdictional claims in published maps and institutional affiliations. 